Al-Bayyinah: Journal of Islamic Law-ISSN: 1979-7486 (p);

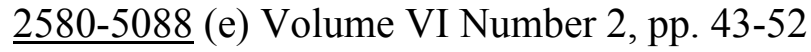

\title{
NIKAH SIRRI MENENTANG PUBLISITAS PERKAWINAN
}

\section{Amir Langko}

(Dosen Tetap STAIN Watampone, Sulawesi Selatan, Indonesia, email: amirlangko.iainbone@gmail.com)

\section{Abstract}

This writing is to explain the importance of publication in marriage. The aim is ti anticipate the society misperception about relation of husband and wife and to strengthen not neglected or lost. In sirri marriage the aspect of publication is neglected on purpose. Based on the study done, in fact, it is found that there are a difference and similarities between sirri marriage in the concept of fig and the reality found in Indonesian society. The defense is clearly sen on the regulation of marriage recording, while the similarity lies on the aspect of keeping secret from other people and the negative impact which arises as the result of keeping secret the marriage.

\section{Kata Kunci: Nikah Sirri, Perkawinan}

\section{PENDAHULUAN}

Praktek nikah sirri yang terjadi di Indonesia dalam banyak kasus menjadi pilihan untuk menikah, karena berasumsi mendapat dukungan syarat bahwa perkawinan itu sah menurut hukum agama. Padahal dalam fiqh klasik nikah sirri itu dilarang, meskipun ada ulama yang mentoleransinya. Pelarangan itu sebenarnya sejalan dengan tujuan aturan perundang-undangan perkawinan tentang pencatatan perkawinan.

Pelarangan nikah sirri dalam ketentuan fiqh itu karena berlawanan dengan pentingnya penyebarluasan yang dikaitkan dengan keberadaan saksi dan penyelenggaraan walimah al 
urusyi. Sementara fenomena nikah sirri yang terjadi di Indonesia tidak berkaitan sama sekali dengan saksi dan walimah. Nikah sirri versi yang terjadi di Indonesia lebih berorientasi pada perkawinan yang tidak tercatat atau perkawinan di bawah tangan. Praktek nikah sirri ini semakin subur akibat adanya pengakuan perundang-undangan perkawinan Indonesia yakni Kompilasi Hukum Islam (KHI) tentang isbat nikah, yakni semacam pengakuan hukum dari peradilan Agama untuk keabsahan suatu perkawinan yang tidak tercatat sebelumnya. Walaupun pengakuan itu hanya secara explisit.

Melihat fenomena nikah sirri di masa sekarang ini, maka dalam tulisan ini penulis mengurai secara mendalam tentang keberadaan nikah sirri sangat menentang publisitas perkawinan yang bisa merusak tatanan dan maksud serta hikmah disyariatkan pernikahan dalam Islam.

\section{PEMBAHASAN}

\section{A. Nikah Sirri dalam Wacana Fiqh Klasik}

Kata sirri berasal dari bahasa Arab yang berarti rahasia dan lambat. Dalam shalat juga ada istilah sir, yakni shalat sir yaitu shalat yang bacaannya dilantunkan dengan suara lambat. Lawannya adalah jahr yakni bacaan shalat yang diucapkan denagn suara lantang hingga orang lain dapat mendengarnya. Dalam konteks pernikahan, nikah sirri berarti pernikahan yang dirahasiakan. Dalam terminologi fiqh, nikah sirri adalah pernikahan yang dihadiri oleh dua orang saksi lalu mereka diminta untuk merahasiakan pernikahan tersebut. imam Malik dalam hal ini melarang, sedang Imam Hanafi dan Syafi'i mentoleransi hal tersebut.

Nikah sirri tidak dianjurkan karena berlawanan dengan urgensi publisitas dalam perkawinan. Urgensi publisitas perkawinan itu dalam wacana fiqh berkaitan dengan saksi dan fungsinya serta anjuran menyelenggarakan walimah al ursyi. Dalil yang populer digunakan untuk menunjuk keabsahan perkawinan yang dikaitkan dengan saksi adalah:

${ }^{1}$ Lihat Wahbah al-Zuhaily, al-Fiqh al-Islam wa Adillatuhu (Juz VII; Beirut: Dar al- Fikr, 1989), h. 71. 


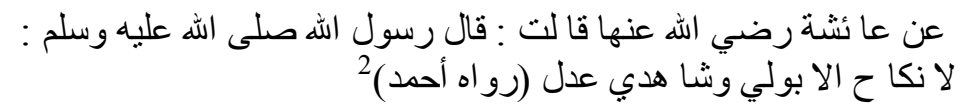

Artinya:

"Dari Aisyah ra. Ia berkata: " Rasul saw. telah bersabda: 'tidak sah nikah kecuali dengan wali dan dua orang saksi". (HR. Ahmad)

Keberadaan saksi dalam perkawinan bukan saja untuk menentukan keabsahan suatu perkawinan, tetapi juga karena saksi mengemban fungsi i'lan yaitu menyebarluaskan kepada khalayak ramai bahwa telah terjadi pernikahan. Tujuannya untuk menghindari isu negatif yang mungkin saja muncul setelah pernikahan karena adanya dugaan hubungan seks di luar nikah. Sekaligus untuk mengukuhkan hak-hak yang timbul akibat akad perkawinan tersebut. Seperti: pengakuan nasab, hubungan mushaharah mendapatkan nafkah, pengukuhan hak waris dan lain sebagainya. Keterkaitan saksi dalam aspek publisitas inilah yang menjadi alasan fuqaha' menempatkannya sebagai syarat sah perkawinan. Implikasinya perkawinan tanpa saksi tidak sah. ${ }^{3}$

Berkaitan dengan peran saksi dalam pernikahan itulah, maka saksi dalam perkawinan itu menentukan keabsahan perkawinan dan fungsinya sebagai $i$ 'lan. Oleh karena itu, fuqaha menetapkan sejumlah persyaratan menyangkut saksi. Seperti Islam, cakap hukum, ${ }^{4}$ adil, ${ }^{5}$ terdiri dari dua orang laki-laki, ${ }^{6}$

${ }^{2}$ Lihat as-Syaukani, Nail al-Autar (Damsyiq: Dar al-'Ilm li Malayin, 1969), h. 184.

${ }^{3}$ Sebenarnya fuqaha kontroversi dalam menentukan posisi saksi pernikahan. Apakah sebagai syarat sah atau syarat sempurnanya perkawinan. Terlepas dari perbedaan itu, intinya mereka sepakat bahwa saksi dalam perkawinan mutlak diperlukan.

${ }^{4}$ Nilai sakralitas dan eksistensi pernikahan kehilangan jika para sasi terdiri dari orang-orang yang tidak cakap hukum. Selengkapnya lihat Sayyid Sabiq, Fiqh al-Sunnah (Beirut: Dar al-Kutub al-'Arabiy, 1989), h. 43.

${ }^{5}$ Syarat adil yang dikemukakan oleh Imam Syafi'iyah. Adil maksudnya adalak konsistensi dalam menjalankan ibadah atau kewajiban agama secara lahiriyah. Eksistensi saksi yang adil itu untuk menunjuk keagungan perkawinan. Jika saksi seorang yang fasik, maka perkawinan kehilangan nilai kesakralannya. Dalam pandangan Imam Hanafiah, jika seorang bapak mempunyai wewenang melangsungkan perkawinan anaknya, maka ia juga dipandang cakap untuk menjadi saksi. Selengkapnya lihat Wahbah al-Zuhaily, op. cit., h. 79. 
merdeka, ${ }^{7}$ bahkan Syafi'iyah mensyaratkan saksi itu melihat. ${ }^{8}$ Sejumlah persyaratan itu ditetapkan supaya peran saksi sebagai i'lan perkawinan dapat secara optimal dilaksanakan. ${ }^{9}$

Selain saksi, penyelenggaraan walimah al-ursy juga berperan mengi'lankan perkawinan. Penyelenggaraan walimah al-ursy bukan sekedar jamuan makan untuk para undangan, tetapi penyebarluasan kepada masyarakat tentang perkawinan dan membedakannya dari perizinan yang umumnya dirahasiakan. Karena alasan inilah Rasul saw., ${ }^{10}$ menyuruh publikasi perkawinan dengan cara menyelenggarakannya di masjid dan memakai musik. Sebab pembeda antara yang halal dan yang haram adalah publikasi.

Sedemikian pentingnya penyebarluasan, maka walimah al-ursy sebaiknya tetap dilaksanakan walaupun dengan pesta sederhana dan hanya mengundang beberapa orang. Dengan alasan publikasi Rasul saw. menyuruh Abd al-Rahman Ibn Auf supaya menyelenggarakan walimah al-ursy walaupun hanya dengan menyembelih seekor kambing. ${ }^{11}$ Karena itulah yang diundang agar datang menghadirinya meskipun ia dalam keadaan berpuasa. ${ }^{12}$ Oleh karena walimah al-ursy menyangkut

${ }^{6}$ Imam Abu Hanifah tidak mensyaratkan lelaki. Menurut Abu Hanifah perempuan boleh menjadi saksi dalam perkawinan. Selengkapnya lihat M. MuhyiddinAbd. Al-Hamid, Ahwal al-Syakhshiyah (Mesir: Dar al-Kutub al'Ilmiyah, 1989), h. 22.

${ }^{7}$ Imam Ahmad Ibn Hanbal tidak mensyaratkan saksi itu merdeka. Kesaksian budak juga dapat diterima apabila menyangkut han dan harta. Lihat Wahbah al-Zuhaily, op. cit., 89.

${ }^{8}$ Menurut Imam Syafi'i ucapan ijab qabul tiddak dapat dipastikan kecuali dengan melihat langsung dari orang yang mengucapkannya. Hanafi berpendapat sebaliknya. Seorang yang tidak bisa melihat atau buta juga diterima sebagai saksi, dengan syarat ia dapat memahami dengan jelas ucapan lafal ijab qabul dari pelaku-pelaku aqad perkawinan. Lihat Wahbah al-Zuhaily, Ibid., h. 90.

${ }^{9}$ Lihat al-Shan'ani, Subul al-Salam (Bandung: maktabah Dachlan, t.th.), h. 117 .

${ }^{10}$ Lihat Ibid., h. 154.

${ }^{11}$ Lihat M. Quraish Shihab, Perempuan (Jakarta: Lentera Hati, 2005), h. 214. M. Quraish Shihab memberi penjelasan bahwa Walimah al-Ursy bukan saja untuk menampakkan kegembiraan dengan terjadinya hubungan pernikahan itu, tetapi juga untuk menjadi saksi sehingga dapat menampik isu negatif yang mungkin saja muncul.

${ }^{12}$ Lihat Ibid., h. 215. 
aspek publisitas maka sebaiknya dilakukan ketika akad atau sesaat setelah akad. Walaupun sebenarnya dapat juga diadakan setelah beberapa lama akad dilangsungkan. Penyelenggaraannya tergantung kebiasaan yang berlaku dalam masyarakat.

\section{B. Fenomena Nikah Sirri di Indonesia}

Nikah sirri adalah isu yang akhir-akhir ini muncul ke permukaan. Dalam realitas masyarakat Indonesia, pengertian nikah sirri itu berbeda dengan pengertian nikah sirri dalam konsepsional fiqh. Kalau di dalam fiqh, nikah sirri berarti pihakpihak yang terlibat di dalam akad melarang saksi mempublikasikan perkawinan tersebut ke khalayak ramai. Sedang dalam tatanan masyarakat Indonesia nikah sirri lebih mengacu pada situasi dan bentuk perkawinan di bawah tangan atau pernikahan yang tidak tercatat menurut peraturan perundang-undangan perkawinan yang berlaku, dan nikah mut'ah. ${ }^{13}$ Untuk yang terakhir walau tidak lazim tetapi biasa dilakukan secara rahasia.

Dalam realitas masyarakat Indonesia ada perbedaan motivasi untuk melakukan nikah sirri antara masyarakat bawah dan masyarakat elit. Dalam masyarakat tingkat bawah nikah sirri biasanya dilakukan karena ketidaktahuan tentang peraturan pencatatan perkawinan, dan tidak sedikit pula yang melakukannya karena alasan untuk menghindari proses administrasi yang sulit dan berbelit-belit, tetapi bukan untuk menghindari publikasi. Artinya banyak alasan mengemuka ketika melakukan nikah sirri. Misalnya: wali enggan menikahkan, orang tua dalam masa kritis wafat (sakratul maut), kekurangan syarat atau berkas administratif baik pada perkawinan monogami ataupun poligami, atau mungkin karena ketidaktahuan.

Kenyataan ini terbalik dengan realitas masyarakatdi perkotaan terutama masyarakat elit. Umumnya nikah sirri terjadi karena kekurangan syarat atau berkas administratif. Ada unsur kesengajaan menghindari proses administratif. Misalnya dalam perkawinan poligami, dimana suami kesulitan mendapatkan izin tertulis dari isteri terdahulu. Untuk

${ }^{13}$ Tiap-tiap perkawinan dicatat menurut peraturan perundangundangan yang berlaku. Pasal 2 ayat 2 Undang-undang No. 1 Tahun 1974 tentang Perkawinan. 
menghindari proses administratif itudan merahasiakannya dari istri pertama, maka suami dalam hal ini melakukan nikah sirri untuk perkawinan kedua, ketiga, dan keempatnya itu. Trend nikah sirri di kalangan elit itu memperlihatkan secara jelas bahwa pernikahan secara sirri itu dilakukan dengan "penuh kesadaran", bukan karena ketidaktahuan tentang aturan pencatatan perkawinan, tetapi untuk menghindari publikasi.

Fenomena nikah sirri ini semakin meluas, karena mendapat dukungan legitimasi syarat, bahwa perkawinan tersebut sah menurut hukum agama. Sedangkan aturan tentang pencatatan perkawinan itu dianggap tidak diatur oleh syarat. aturan tentang pencatatan itu hanyalah merupakan tambahan syarat administratif, tanpa ada pengaruhnya terhadap sah dan batalnya perkawinan. Keabsahan perkawinan tidak tergantung dengan pencatatan perkawinan, tetapi ditentukan dengan terpenuhinya semua rukun dan syarat perkawinan. Apabila semua unsur-unsur pembentuk bagi akad sudah terpenuhi secara sempurna seperti yang diatur dalam syarat, maka akad nikah itu secara syarat telah dianggap sah sehingga halal bergaul sebagaimana layaknya suami isteri yang sah. Dan anak yang lahir dari hubungan tersebut sudah dianggap anak yang sah.

Agaknya pemahaman "sah menurut hukum agama" inilah yang menyebabkan banyak orang melakukan nikah sirri. Disamping itu adanya sikap yang mendua dalam ketentuan peraturan perundang-undangan perkawinan yang mengatur tentang isbat nikah. Seperti yang tercantum dalam pasal 7 ayat 2 KHI yang berbunyi: "dalam hal perkawinan tidak dapat dibuktikan dengan akta nikah, dapat diajukan isbat nikah ke Pengadilan Agama".

Dan ayat 3 yang berbunyi:

"isbat nikah yang dapat diajukan ke Pengadilan Agama terbatas mengenai hal-hal yang berkenaan dengan:

a. Adanya perkawinan dalam rangka penyelesaian perceraian,

b. Hilangnya akta nikah,

c. Adanya keraguan tentang sah atau tidaknya salah satu syarat perkawinan,

d. Adanya perkawinan yang terjadi sebelum berlakunya UU No. 1 tahun 1974, 
e. Perkawinan yang dilakukan oleh mereka yang tidak mempunyai halangan perkawinan menurut UU No. 1 Tahun 1974.

Kemudian ayat 4 yang berbunyi: "Yang berhak mengajukan isbat nikah ialah suami isteri, anak-anak mereka, wali nikah dan pihak yang berkepentingan".

Ketentuan isbat nikah seperti yang diatur dalam pasal 7 KHI tersebut, secara eksplisit mengindikasikan pengakuan terhadap keabsahan pernikahan yang tidak tercatat agar kemudian dicatatkan. Dan tentu saja peluang "isbat nikah" ini agar "dicatatkan" menguntungkan kepada pihak-pihak yang melakukan nikah sirri tersebut.

Adanya pengakuan eksplisit terhadap nikah sirri melalui isbat nikah dan ungkapan "sah menurut hukum agama" ini jelas bertentangan dengan pentingnya publikasi dalam perkawinan. Perkawinan hendaklah dipublikasikan. Nabi saw. bersabda:

$$
\begin{aligned}
& \text { عن عائشة رضي الله عنها قالت : أن رسول الله صلى الله عليه }
\end{aligned}
$$

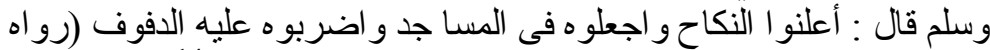

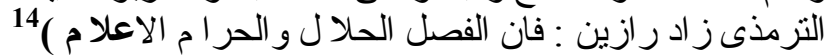

Artinya:

"Dari Aisyah ra., ia berkata: "sesungguhnya Rasul saw. bersabda: "umumkanlah pernikahan, selenggarakanlah di mesjid-mesjid, dan pukullah rebana. (HR. Tarmidzi). Razin menambahkan: "Sesungguhnya pembeda antara yang halal dan yang haram adalah pengumuman (penyebarluasan beritanya)."

Hadis ini menjadi dalil perintah menyebarluaskan (mempublikasikan) pernikahan dan bukan merahasiakannya. Publikasi perkawinan itu penting karena:

1. Menyangkut hubungan suami istri, agar tidak diduga melakukan perzinahan. oleh karena itu, publikasi itu bertujuan untuk menghindari tuduhan dan kecurigaan masyarakat.

2. Menyangkut hak-hak isteri dan anak, agar hak-hak mereka misalnya, hak nafkah, pengakuan nasab, dan hak waris tidak

${ }^{14}$ Lihat Imam at-Turmudziy, Sunan at-Turmudziy (Mesir: Dar al-Fikr, 1979), h. 498. 
hilang. Merahasiakannya dapat berdampak kacaunya hakhak hukum anak yang dihasilkannya. Karena lelaki bisa saja menolak dan menyangkalnya.

\section{Menentang Publikasi dalam Nikah Sirri}

Adalah kemestian jika di dalam perkawinan publikasi itu diperlukan. Urgensi publikasi perkawinan dikaitkan dengan saksi dan fungsinya serta anjuran menyelenggarakan walimah al-ursy, karena keduanya mengemban fungsi $i$ 'lan. Oleh sebab itu nikah sirri dilarang, karena bertentangan dengan fungsi saksi dan tujuan penyelenggaraan walimah. Keberadaan saksi dan walimah sebagai aspek publikasi bertujuan untuk mengukuhkan hak-hak isteri dan anak serta menghindari dugaan terjadinya hubungan seks di luar nikah.

Sementara nikah sirri yang terjadi di Indonesia, sama sekali tidak terkait dengan saksi dan penyelenggaraan walimah al-ursy. Nikah sirri lebih dikarenakan tidak adanya legalitas perkawinan, akibat perkawinan itu tidak dicatatkan atau di bawah tangan. Untuk sebagian masyarakat, nikah sirri itu dilaksanakan untuk menghindari publikasi. Ada semacam upaya untuk merahasiakan perkawinan tersebut. misalnya terhadap isteri, keluarga dan masyarakat seperti dalam kebanyakan perkawinan poligami.

Akan tetapi ada kesamaan pelarangan nikah sirri dalam wacana fiqh dan hukum perkawinan di Indonesia, yakni menghindari tuduhan dan persangkaan perzinaan, serta untuk mengantisipasi agar isteri dan anak tidak kehilangan hak-haknya akibat perkawinan sirri tersebut. untuk itulah diperlukan pencatatan perkawinan. Dengan memiliki surat akta nikah secara resmi yang dikeluarkan pihak yang berwenang, maka kemudharatan itu dapat dihindari.

Intinya nikah sirri dilarang untuk menghindari kemudharatan terhadap isteri dan anak. Sesuai dengan kaedah ushul:

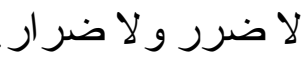

Karena itulah, menurut penulis nikah sirri itu diharamkan. Pentingnya publikasi perkawinan bukan saja terkait dengan saksi dan terpenuhinya unsur-unsur pembentuk akad secara sempurna tetapi perlu dibuktikan melalui pencatatan perkawinan yang dibuat dalam bentuk akta nikah. Sehingga 
perkawinan tidak saja sah menurut hukum agama tetapi juga sah menurut hukum negara. Selain sebagai bukti, pencatatan perkawinan dilakukan untuk ketertiban perkawinan bagi masyarakat Islam Indonesia. ${ }^{15}$ Sebenarnya aturan tentang pencatatan perkawinan secara eksplisit sudah termaktub dalam QS. al-Baqarah ayat 282. Ayat tersebut memang tidak menyinggung langsung tentang perkawinan tetapi difokuskan pada transaksi hutang piutang. Akan tetapi dipahami bahwa ayat tersebut berkaitan dengan akad secara umum. Artinya setiap melakukan transaksi (akad) sebaiknya dilakukan pencatatan. Tujuannya bukan saja sebagai bukti kebenaran terjadinya suatu tindakan tapi juga sebagai upaya antisipasi adanya ketidakjelasan di kemudian hari.

Adanya pengakuan sah menurut hukum agama dalam nikah sirri sehingga dapat dibenarkan, tidak sejalan dengan pendapat penulis.menurut penulis nikah sirri berdampak negatif secara psikologis dan sosiologis karena tidak mendapat dukungan normatif yakni bukti otentik berupa akta nikah. Oleh karena itu, nikah sirri tidak dapat dibenarkan. Berdasarkan kaedah ushul:

$$
\text { درء المفا سد مقدم على جلب المصالح. }
$$

"Menolak kemudharatan lebih diprioritaskan daripada menarik kemaslahatan".

Sikap ambiguitas peraturan perkawinan ditambah pengakuan sah menurut hukum agama sangat merugikan perempuan. Oleh karena itu, atas pertimbangan menghindari kemudharatan nikah sirri diharamkan. Di Indonesia praktek nikah sirri menguat di basis masyarakat karena agama menjadi dasar pembenarannya dan inilah yang menjadi patokan. Oleh karena itu, menurut penulis hal itu harus diperhatikan secara mendalam. Karena pengukuhan fiqh secara formalistik ternyata mengorbankan kelompok masyarakat lemah, khususnya perempuan.

${ }^{15}$ Bunyi pasal 5 Kompilasi Hukum Islam (KHI) adalah agar terjamin ketertiban perkawinan bagi masyarakat Islam setiap perkawinan harus dicatat. Selengkapnya lihat Departemen Agama RI, Kompilasi Hukum Islam (Jakarta: Dirjen Pembinaan Kelembagaan Agama Islam, 2000), h. 58.

${ }^{16}$ Lihat al-Suyuti, al-Asybah wa al-Nazhair (Semarang: Toha Putra, 1968), h. 39. 
Kalau hal ini dibiarkan, berarti fiqh terlibat dalam proses penganiayaan terhadap perempuan. Sisi fiqh ini harus dibenahi. Bukan fiqh yang diubah, tetapi pengertian penerapannya yang harus dipertimbangkan. Fiqh itu hukum dan hukum itu bergantung pada bagaimana melaksanakannya. Hukum tidak harus dilaksanakan begitu saja. Hukum merupakan perangkat yang akan menjalani tercapainya sasaran. Sasaran itu adalah kemaslahatan.

\section{PENUTUP}

Nikah sirri berkembang di dalam masyarakat karena mendapat dukungan agama yang dijadikan dalil pembenarannya, ditambah sikap ambiguitas peraturan perkawinan tentang isbat nikah semakin mengukuhkan keberadaan nikah sirri di Indonesia. Kedua dasar pembenaran itu banyak merugikan masyarakat terutama perempuan dan anak-anak. Oleh karena itulah nikah sirri dilarang.

\section{DAFTAR PUSTAKA}

Departemen Agama RI. Kompilasi Hukum Islam. Jakarta: Dirjen Pembinaan Kelembagaan Agama Islam, 2000.

Al-Hamid,M. MuhyiddinAbd. Ahwal al-Syakhshiyah.Mesir: Dar al-Kutub al-'Ilmiyah, 1989.

as-Syaukani. Nail al-Autar. Damsyiq: Dar al-'Ilm li Malayin, 1969.

Sabiq, Sayyid.Fiqh al-Sunnah. Beirut: Dar al-Kutub al-'Arabiy, 1989.

al-Shan'ani.Subul al-Salam. Bandung: Maktabah Dachlan, t.th.

Shihab, M. Quraish.Perempuan.Jakarta: Lentera Hati, 2005. al-Suyuti.al-Asybah wa al-Nazhair.Semarang: Toha Putra, 1968. at-Turmudziy, Imam.Sunan at-Turmudziy.Mesir: Dar al-Fikr, 1979.

Undang-undang No. 1 Tahun 1974 tentang Perkawinan.

al-Zuhaily, Wahbah.al-Fiqh al-Islam wa Adillatuhu.Juz VII; Beirut: Dar al- Fikr, 1989. 